\title{
On Artistic Mood Representation in Landscape Paintings
}

\author{
Wenxiu Li \\ School of Art and Design \\ Huanghe Science and Technology College \\ Zhengzhou, China 450046 \\ E-mail: 554287746@qq.com
}

\begin{abstract}
This paper put forward the traditional cultural spirit is China's fundamental viewpoint for nationalization of painting, clarified the "artistic mood" theory of Chinese painting was an important feature and representation of Chinese traditional culture, and further discussed the significance of specific means of "artistic mood" generation in the context of landscape painting.
\end{abstract}

Keywords—painting; sketch; context; artistic mood

\section{INTRODUCTION}

Landscape Painting is an essential part for all painting students in their learning process and in their painting creation, especially for the painters who love natural scenery in a life and who take natural scenery as creative theme. Landscape painting has unique advantages in training students' skill of color feeling and color expression, which is nonreplaceable for indoor still life sketch and character sketch. For students, the basic elements of Landscape Painting, such as composition, color and strokes can naturally be improved and mastered after a scientific training, but the "artistic mood" in the context of landscape painting is much more difficult relatively. Li Keran said, "the artistic mood is the soul of Arts, and is the essence of the objective things, which is cultivated with people's thoughts and feelings, and achieves a harmony of scenery to feeling by highly artistic process, expressing emotion by taking advantage of a scene, thus an artistic realm of things is presented. This is called artistic mood." Mr. Li's words also fully show the importance of artistic mood for Arts. Here, the author in the perspective of "artistic mood" in landscape painting, discussed the appreciation style of landscape painting, because a important appreciation standard for Landscape Painting and all paintings is just the "artistic mood". A painting without "artistic mood" has no artistic quality.

\section{The Historical Mission OF PAINTING FOR CHINESE NATIONALIZATION}

In China, painting is a new type shipped from the foreign country, which began in the beginning of the last century, resulted from the activities that Nanjing Liangjiang Excellent Normal School first set up the specialized subject of Western painting and at the same time the Qing government sent students to study painting in the West (mainly French) and the Toyo (Japan). And just when the students studying abroad returned to China for running school and teaching in the late 1920s, painting really became a new kind of painting in Chinese painting circles. In the early days of New China, there are two dominant styles of painting in Chinese painting, of which one is the realism with $\mathrm{Xu}$ Beihong as the representative who advocated a realist depiction of real life and the other is the expressionism with Lin Fengmian as the representative who advocates "absorption of foreign technique". Following Kang Youwei, as a practitioner of Western realistic techniques and realistic spirit in the arts, $\mathrm{Mr}$. $\mathrm{Xu}$ regards the social function of art beyond all, and he pursues the belief of art serving the life and the public. At that time, Chinese people were struggling for the survival and salvation of the nation, his realist method became the best form to enlighten conscience and awaken the nation. In the historic period of Chinese and Western cultures contact, $\mathrm{Mr}$. Xu's choice of realistic painting met the need of the era, and it has a strong realistic significance. While, Lin Fengmian went a new way of Chinese and Western arts concordance, and by the influence of Cai Yuanpei's thought of "inclusion and combination" and "concordance between Chinese and West arts", he advocated the belief of "serving Chinese painting by integrating the western technique". Through the Cultural Revolution, such as the "Red Brightness" in color and "Gao Daquan" in figure, and after the reform and opening up of China, Chinese paintings make a great progress, and then in the following a decade Chinese painting tried all the styles and genres that formed in the west for a century, but the whole process is still a kind of imitation, reference and study of the West. In this process, the seniors in Chinese painting are striving for Chinese nationalization of Chinese painting, but the results are not perfect. Why is this? Mr. Yuan Yunsheng revealed the truth: "Recalling Chinese art movement in the past century, our largest defect is probably we lost our confidence for Chinese national culture and spirit." We can say that only a person or a nation, who really finds its own spiritual source, is able to make a conscious practice and to engage a historic creation, or it only keeps groping in the dark and gets half the results with double the effort. "Today, in the process of global cultural integration, how to find and reconstruct the 
fundamental characteristics of Chinese culture, to make Chinese painting developed in mainstream style and overall tendency according to the cultural fundament and the inner spirit of the nation, and to free explore the spirit, new life and new form of culture in the transnational context of postcolonialism theory is a very important task before us when we focus on the future development of Chinese painting and make investigation and thinking of Chinese painting in the view of the whole world. In a word, the Chinese nationalization of painting is related to the inclusion of paintings and Chinese traditional culture after the final analysis, and the author believes the" artistic mood" is just a feasible inclusive point.

\section{III. "ARTISTIC MOOD" OF LANDSCAPE PAINTING IS THE BREAKTHROUGH POINT OF TRADITIONAL CULTURE}

"Artistic mood" is an important category of Chinese Aesthetics and is one of the important features of Chinese painting. The word of "Artistic Mood" first emerged in the creative writing and criticism theory in the Tang Dynasty. The concept of "artistic mood" is applied to the painting, mainly in the Ming Dynasty and the Song and Yuan Dynasties when the landscape painting got a rapid development. In the current view, the "artistic mood" no longer has much difference from the "image" that represents the spirit of Chinese traditional culture and art, and both of them are involved in works of art, showing both the materialization of soul and the emotional embodiment of matter. The unity of mind and matter, and the harmony of scene and feeling, both come from the thought of "Harmony between human and nature" in traditional culture. While the "image" theory is converted from the "Tao" thought in traditional culture, and the "artistic mood" is originated after Buddhism is introduced to China, for which Mr. Min Ze has given a very clear explanation: "... and the theory of artistic mood is different, and although it is related with the "Book of Changes", "Zhuangzi" and etc, it is originated mainly after Buddhism is introduced to China, and resulted from Buddhist philosophy, statues, paintings and other effects. It began its embryonic stage in the Northern and Southern Dynasties, and then is more commonly used in literature and art after the Tang Dynasty". During the period of Wei and Jin Dynasties in China, Metaphysics rose and individual consciousness roused, and the cultural tradition of "Advocating Practice and Advocating Unity" was faced with unprecedented challenges, so the change of cultural character was imperative under that situation. In a lucky coincidence, the Buddhism that was introduced to China in the Eastern Han Dynasty just at that time entered into the spirit of Chinese culture, and it produced an effective role in deconstructing and remodeling the spirit of the ancient culture. Buddhism advocates "mood", so it expedites the production of "artistic mood" history when it penetrates into the hisotry of Chinese local culture. the culture of Confucianism and Taoism that has strong blending and acceptance capability, make change of it after absorbing Buddhist thought, and make it blended constantly, and finally make it a representative thought with tripartite balance of forces among Confucianism, Taoism and Buddhism, meanwhile it makes China's cultural and artistic spirit changes accordingly. "After the theory of 'Mood' was applied to painting in the Five Dynasties and Song and Yuan Dynasties, the landscape painting has stepped from its infant stage of map-making style into the stage of advocating ' reality' and valuing 'sketch', and artists began to focus on the painting of reality and put forward the theory and artistic creation of 'appreciating landscape with infinite emotions' and 'valuing its spirit and ignoring its form', for purpose of 'Theory of smoothing spirit' and ' Theory of making mind peace'". The theory of " Mood" is proposed and later becomes one of the important criterions for appreciating Chinese traditional paintings, at the same time it is also one of the important features of Chinese traditional cultural and artistic spirit, so the mood in landscape painting is a important manifestation of landscape painting blending into traditional culture, and also an effective way of painting to achieve Chinese nature and nationalization.

\section{What Is ThE "MoOD" And How To Blend ThE "MOOD" IN THE LANDSCAPE PAINTING}

In the above, it is discussed that mood refers to works of art that should be the materialization of soul and the emotional embodiment of matter, with the unity of mind and matter, and the harmony of scene and feeling. It may be Sikong $\mathrm{Tu}$ in the Tang Dynasty who made a gnomic definition of the "mood", where he pointed out that the mood is characterized by "Beyond the surface, mastering the core of things development" (from Sikong Tu's "Twenty-four Styles of Poetry"), by "showing a infinite time and space from the limited sight", and by "what a unattainable poetry scene before the imminent, but a tangible feeling" (ditto, from Sikong Tu's "Twenty-four Styles of Poetry"). And it may be Yan Yu in the Song Dynasty who made much and wonderful elaboration of "mood" that has been recognized by the public. He said: "the poets in the Tang Dynasty focused on the charm of poetry, with superlative poetic art, showing no traces of effort, like a antelope standing upside down with its horns hanging on a three, so their poetry is ingenious, intensive and exquisite, hardly to grasp directly, like the sound in the air, the color of appearance, the moon in the water, the image in the mirror, with limited words but indefinite meaning." (From Canglangshihua - a defence of poetry), which is the highest aesthetic realm of "Harmony between human and nature" in traditional culture and thought One part of "artistic mood" mainly expresses the passion, mind and thinking in the subject of art works, and the other part mainly presents the inner feeling in a certain artistic image by an artistic means. The entire "mood" in arts is a natural reflection of objective reality, but not an imitation or copying. The "mood" in arts often has difference from the real examples in the life, and just because of processing and reconstruction by arts, the "mood" gets rid of the limitations of real space and the constraints of "image". In the context of landscape painting, "artistic mood" is produced with the painting as media, and expressed by the hue, line, composition and others. Just as the "mirror of painting" by the words of Leonardo Da Vinci who is one of the three outstanding figures during the Renaissance, the artistic mood is generated from the unity of subject and object, and the reflection of high harmony of natural beauty, lift beauty and 
artistic beauty, that is characterized by a painter's "emotions and conception in their imitation of nature". Meanwhile it is the concentrated representation of objective things by art reproduction and subjective spirit, which combine the beauty of mood in Chinese traditional painting. The mood in painting, just like the moon in the water and the flower in the mirror, is real but hardly to touch, reflecting the "conception beyond the image" that is spirituality and character of Chinese traditional painting. So how should we introduce the aesthetic category of traditional "mood" in the context of landscape painting? To solve this question, the painters, the painters' temperament, personality as well as their unique aesthetic interest and their particular emotional expression must be involved. All these should be attributed to painters' literacy eventually. "Creation" is related to the "soul", and if there is no ability of "creation", the "soul" has no foundation. in Landscape Painting, "creation" and "soul" are the common sources to feel the vitality of objective nature and understand aesthetic interest, and neither is dispensable. Thus, the accomplishment of "mind", also the accomplishment of culture, is the key to generate the mood and to introduce the Aesthetic Category of Traditional Culture into the context of Landscape Painting.

\section{SEVERAL SPECIFIC GENERATION WAYS OF MOOD IN THE CONTEXT OF LANDSCAPE PAINTING}

And then how should we generate artistic mood in landscape painting. First, we should have a deep understanding and grasp of Eastern and Western artistic trait, for which the senior Lin Fengmian had a good conclusion. He said: "Western art trends to the objective in form, and is often short of emotional expression due to its excessive form..., while oriental art trends to the subjective in form, and is often unable to show the need of emotions due to its deficient form... so in fact the shortage of Western art is just the advantage of Oriental Art. If the shortage and the advantage of western and Chinese arts complement each other, the new art will generate in the world at present." Mr. $\mathrm{Wu}$ Guanzhong who is famous in Chinese and foreign painting circles, just is the typical representative to advocate "the shortage and advantage complementing each other" between Western and Chinese arts. Mr. Wu applied Chinese charm and artistic mood as his painting fundamental and combined model, color, form and other means to educe the "generation of new art in the world". In addition, the entertainment (cheerful feeling) and fancy (smoothing spirit) beyond the matter is also critical for the generation of artistic mood in the Landscape Painting. As a painter, we should be able to feel the specific figure and characteristics of the nature, and also realize the life, spirit and inner feelings of the nature, that is to say, the cheerful feeling and fancy beyond the matter is the key link of landscape painting to go beyond natural appearance and represent the life of the nature. The mood beyond the matter is an important stage of painting, the world of a painter beyond the nature, and the spiritual world beyond the nature. When wandering in the nature, we should first see some things with our eyes and then feel them. So for the feeling beyond the matter, only when we have open mind, we are cheerful and relaxed. The author thinks there is nothing besides the specific operation methods as the following: the law of layout, the border of color, the beauty of strokes and the signification of subject matter. First we talk about the law of layout, and it refers to the composition of a picture in the Landscape Painting, for which we may not make a copy and facsimile, and it should be the reflection of a painter's aesthetic psychology in a painting. "Meeting by mind in place of eyes" rightly illustrates this idea. Ancient Chinese landscape painter Ma Yuan made this painting only in a corner of the whole layout, which is known as "Ma's A Corner". The landscape and its meaning in his painting show the world of the Song Dynasty has been deprived of the southeast corner, which fully reflects his concern for the national fate with his aesthetic mood. The border of color in the landscape painting more can learned from and referred to Chinese traditional painting, such as Su Shi's painting of Red Bamboo and Wang Wei's ink painting of Banana in Snow, in which the things are very different from the objective, but they give people a sense of reality beyond the fact. When people experience the realm of art, they bring the appreciators a sense of beauty from the painter's spirit more than that from the color of painting, and such sense of beauty can be realized by means of the painting. And then we talk about the beauty of strokes, where the "beauty" is still regarded as a realm of painting. There are innumerable masters at all times and in all over the world who express the realm of painting by their brush strokes, and among them Vincent van Gogh, a post-impressionist painter painted the "Starry Night" that is a typical example. The whole works of "Starry Night" has a smooth and twisting brush stroke, where the sky with blue and yellow vortex seems like a ray of repeatedly wandering light, making us dizzy and excited. This clearly shows Van Gogh's thoughts and his strong desire for creation. Finally, let's speak about the signification of subject matter. In the landscape painting, subject matter is also important, and it can clearly show a painter's emotions, such as the ancient Chinese artists Zhu Da who painted "A Fish with Wide Eyes" and "A Bird without Eye" and Zheng Nan who pained "Orchid without Roots", all express their emotions completely by dint of the painting.

\section{CONCLUSION}

Of course, the above discussion of the author about the mood in the context of Landscape Painting, is mainly related to the problems how to practice and achieve. The achievement of mood in the context of Landscape Painting is finally related to the analysis on traditional culture and on the painters' accomplishment of culture and national confidence.

\section{REFERENCES}

[1] Wu Guanzhong. The Style in the Region of Wu [M]. Jinan: Shandong Pictorial Publishing House, 2008.

[2] Pan Gongkai. Lyricism - The combination of Chinese Future Painting and Traditional Culture and Spirit [J]. Chinese Painting, 2005 (1): 30.

[3] The Ministry of Education. Trial Textbook (First Volume) of Fine Arts in Junior High School of Three-year System for Nine-year Compulsory Education[M]. Beijing: People's Fine Arts Publishing House, 1993 
[4] Tong Qingbing. Art and Human Psychology [M]. Beijing: October Art Publishing House, 1990.367,368.

[5] Hua Tianxue. On the intersection of All Countriesat All Times: Theory of Wu Guanzhong [J]. On Art History, 1995 (2).

[6] Liu Chun. The pursuit of National Artistic Spirit - Record on Interview with Yuan Yunsheng [M]. Kunming: Yunnan Fine Arts Publishing House, 2003. 